\title{
Effects of Ambient Temperature on Acute Exacerbations of Chronic Obstructive Pulmonary Disease: Results from a Time-Series Analysis of I 433 I 8 Hospitalizations [Corrigendum]
}

Zhang Y, Liu X, Kong D, et al. Int J Chron Obstruct Pulmon Dis. 2020;15:213-223.

The authors have advised due to an error at the time of figure assembly, Figure 4 on page 218 is incorrect. The correct Figure 4 is shown below.
The authors apologize for this error and advise it does not affect the results of the paper. 
Mean temperature

Extreme cold

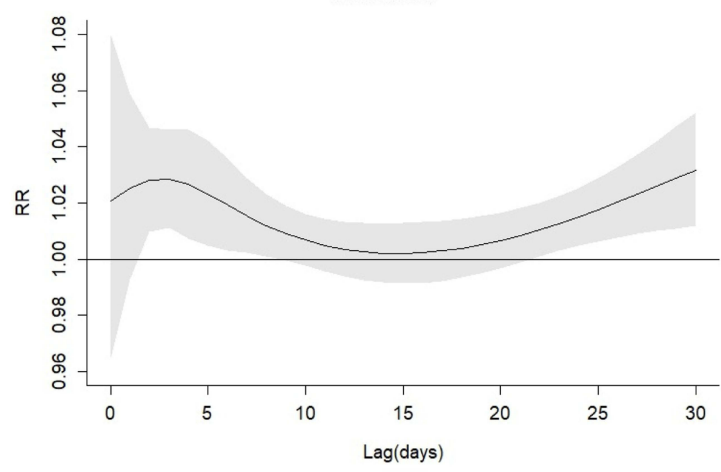

Moderate cold

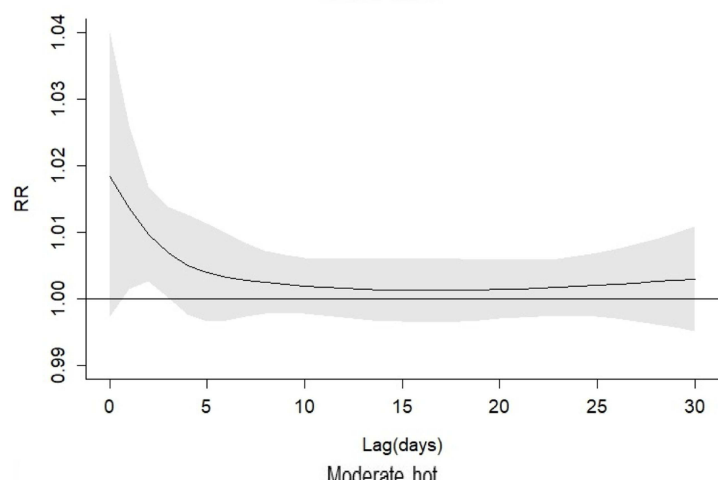

Moderate hot

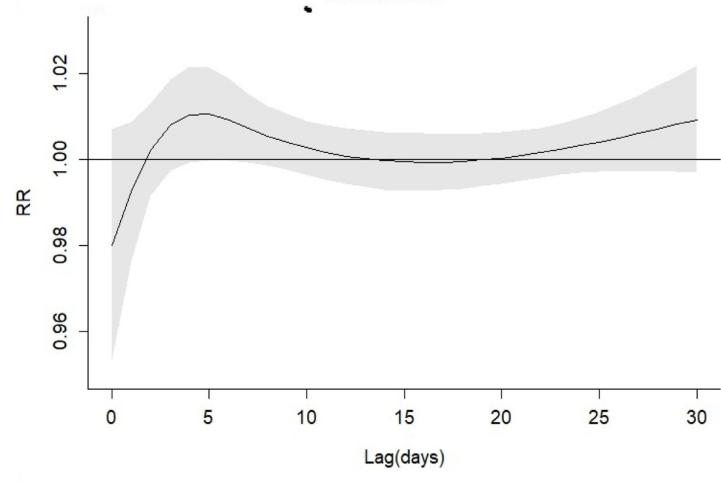

Extreme hot

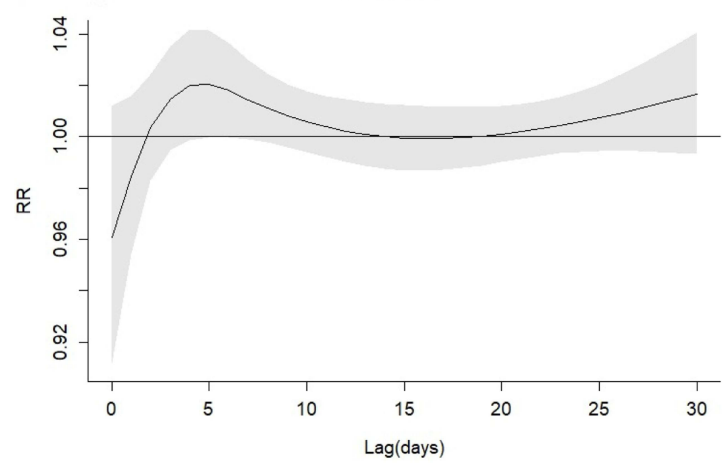

Apparent temperature

Extreme cold

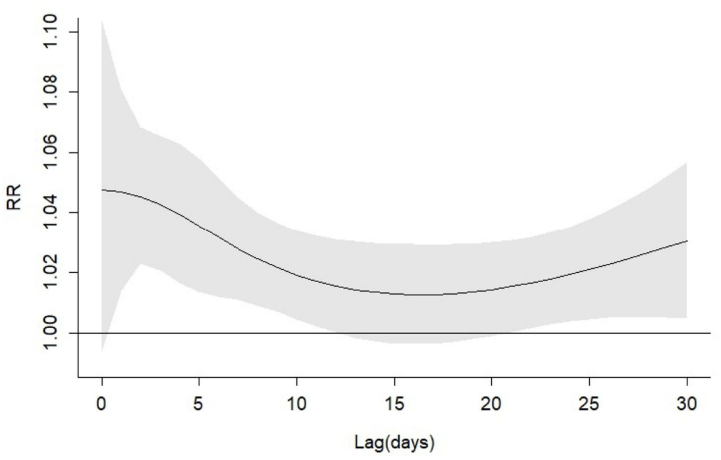

Moderate cold
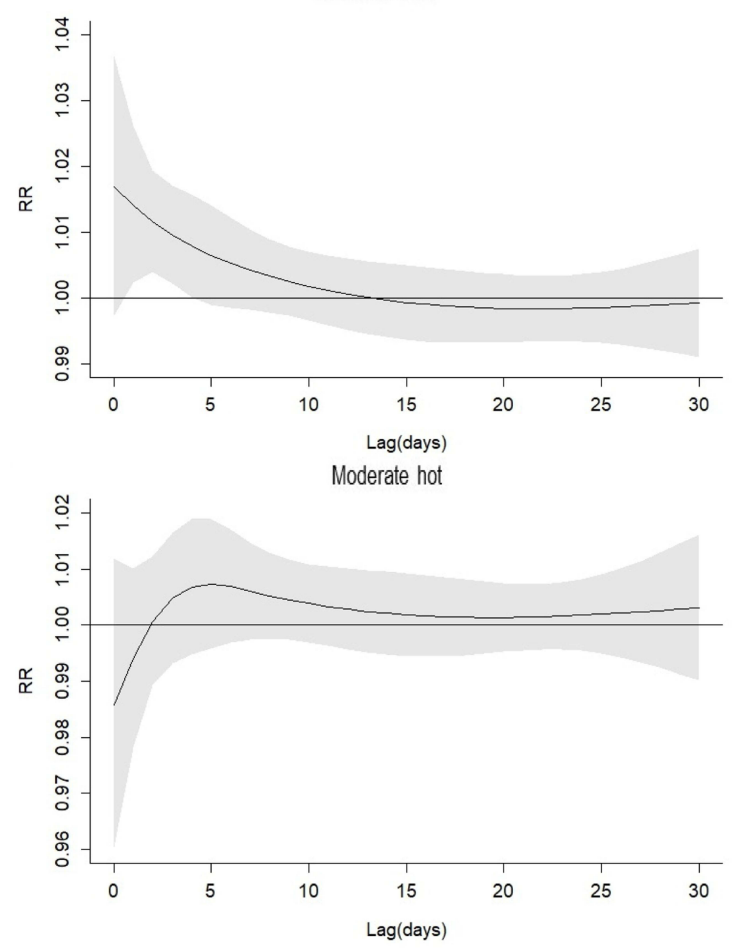

Extreme hot

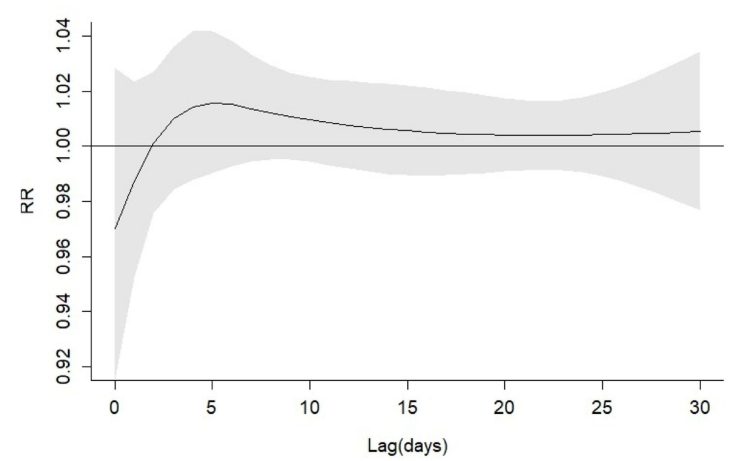

Figure 4 The effect of mean temperature $\left({ }^{\circ} \mathrm{C}\right)$ and apparent temperature on AECOPD hospitalizations along days of lag. The black lines are relative risks and grey regions are $95 \%$ confidence intervals.

Notes: The definitions of extreme cold, moderate cold, moderate hot, and extreme hot temperatures are the same as those in the footnotes of Tables 3 and 4. 


\section{Publish your work in this journal}

The International Journal of COPD is an international, peer-reviewed journal of therapeutics and pharmacology focusing on concise rapid reporting of clinical studies and reviews in COPD. Special focus is given to the pathophysiological processes underlying the disease, intervention programs, patient focused education, and self management protocols. This journal is indexed on PubMed Central, MedLine and CAS. The manuscript management system is completely online and includes a very quick and fair peer-review system, which is all easy to use. Visit http://www.dovepress.com/testimonials.php to read real quotes from published authors. 